\title{
$[2]$
}

\section{Fieldwork in Taiwan: Becoming a Little Chinese}

The Chinese live in many climates, speak many languages, and follow widely differing customs. But they all share at least one thing: a strong and sophisticated belief that human relationships are more important than anything else. They are, indeed, so important that they cannot be left to the chance of individual idiosyncrasy but are governed by clear-cut and wellknown rules to which everyone must conform. Those who do not-foreigners and rare Chinese eccentrics-are excluded from the inner circles of friendship and trust where all of life's real business is transacted. To learn as an anthropologist from Taiwan's people about their lives, I had to learn those rules and how to put them into practice in our relationships. I had to become a little bit Chinese.

To do so I had to change, at least temporarily, many ways of behaving, such as basic body language, that had always seemed perfectly natural to me. Chinese women, I came to understand, seem to tuck their head, limbs, and torso into a tighter, neater package than I was accustomed to doing; my relative looseness of posture appeared disrespectful or at least slovenly. Belching was socially acceptable, while blowing one's nose was not.

The Chinese language I had learned in the United States, which was supposed to be my main channel of communication, was full of traps and confusions, for I knew only how to say in Chinese what an American would say. A Chinese, in similar circumstances, often comes out with something quite different. Where we make small talk about the weather or current events, for example, they inquire if a new acquaintance has brothers and 
sisters, or ask the amount of her salary. Where we are taught to accept a compliment with quiet thanks, a Chinese cannot comfortably do so, being obliged modestly to deny having any positive qualities.

Chinese etiquette presented me with many challenges. Seeing guests spit chicken bones and melon seeds onto the table or the floor at a formal dinner startled me, but I must have seemed equally rude to my fellow diners for following my hard-to-break habit of drinking when I felt thirsty, rather than politely toasting someone before sipping. Dinner guests are insistently helped to portions throughout a meal by the host or hostess, who is mortified at the sight of an empty bowl. I finally learned not to finish everything on my plate, thereby allowing my host to stop feeding me. This kind of hovering solicitude is one of the essentials of Chinese etiquette, one I found hard to like and harder yet to remember to copy. Small exchanges of courtesy-a friend offering to hold one's handbag on a crowded bus or taking her hand to cross a street, one person necessarily treating rather than each person paying her own way at restaurants, and the like-are constant, and are paralleled by the frequent exchanges of gifts that cement friendships.

Chinese behavior differs from American, too, in its emphasis on preserving people's "face," or dignity, in ways that sometimes lead to indirection and apparent evasiveness. When asked, for example, to do something she does not really feel able to do-although Chinese are very willing, by American standards, to help their friends-a Chinese rarely refuses directly. One must learn to detect more subtle signs of unwillingness, and must learn as well that to give a flat refusal to a request is dismaying, and even offensive.

Etiquette exists in part to smooth and order human relations, to create a framework within which friendship is possible. The meaning of friendship itself differs from the American version, however. Chinese make few casual, short-term acquaintanceships as Americans learn to do so readily in school, at work, or while out amusing themselves. Once made, however, Chinese friendships are expected to last and to give each party very strong claims on the other's resources, time, and loyalty By learning these and a multitude of other cultural differences, I tried slowly to behave more like the people I wished to study.

\section{First Encounters}

I collected these life histories during a brief span of time, in the autumn of 1980. I could not have done this work on my first field trip to Taiwan, 
from 1968 to 1971, or, probably, during my second, one-year trip in 197475. These years of study and direct experience with Chinese people were necessary for me to learn how to be trustworthy and sincere in a Chinese way. With that knowledge, I felt ready to begin the highly personal fieldwork in which the anthropologist creates a picture of a culture and its changes by digging deeply into people's memories of their lives. I will examine here some of the complex prerequisites to what may appear to be the simple task of writing the life stories of nine ordinary people.

On my first field trip to Taiwan, I attained a modest fluency in Mandarin Chinese and a smattering of the Taiwanese language, collected enough information about work, worship, and politics to write a doctoral dissertation on the organization of an urban neighborhood, and began to come to grips with the multitudinous differences that separate American and Chinese culture. When I left Taiwan after that first field trip, my head held far more difficult questions about the nature of Chinese society than I had come with. One that especially puzzled me then was why some Chinese seemed so exceptionally friendly, helpful, and hospitable, while so many others were startlingly rude, cold, and "slippery." If ever a culture seemed riddled with contradictions, it was this one.

Part of the bafflement I felt at the apparent unpredictability of Taiwan's complex society was the result of a simple accident of my personal circumstances during those years. I was dividing my time among three groups of people who represented very different social categories of Chinese and who had different versions of "Chinese culture" to teach me.

I met the first as I studied language from teachers chosen for the standard purity of their Mandarin accents. My first Chinese associates, then, were well-educated women and men from the cultural centers of northern China, such as Beijing. Though few were rich, their prestige was substantial, and some were linked to wealthy and powerful families. All were post-World War II immigrants to Taiwan, "Mainlanders," and selfconsciously proud of it. They taught me, along with language, as much formal politeness and customary behavior as they thought I needed, and they answered my questions about Chinese culture out of their own experience and sense of what was proper to reveal. To them I was a hard-working graduate student undertaking the clear-cut task of language learning, which many of them had also undertaken as they studied English. Soon I would be a university teacher. What I was and what I was to become were clear to them, and so was our honorable relationship as student and teacher.

My encounter with the second "group" began with just one person: Mrs. Zhang, the lively, cheerful woman engaged as housekeeper for my small household. She was also a Mainlander-the clear Shandong accents of her 


\section{Chinese Working-Class Lives}

native province still fall most naturally on my ears-but not a member of the immigrant elite. She and her husband had arrived after the 1949 retreat of the Nationalists to Taiwan, along with the more than a million other common soldiers and their households that make up most of Taiwan's Mainlander population. Through her I met her family, her friends, and their families-an ever-widening circle of military men and domestic servants to whom I was a recognizable and prestigious person-a university professor-in-training and a reasonably fair and generous employer, to be treated with a pleasing mixture of intimacy and respect.

The third category of Chinese with whom I spent much time consisted of the inhabitants of my chosen field neighborhood, Prosperity Settlement. These involuntary recruits to anthropology were the families of shopkeepers, construction workers, low-level clerks, laborers, and small-scale manufacturers who occupied a cluster of old residences in the recently expanded suburb of Taibei where I was living. Commercial astuteness and a wide network of social ties-not education - were the foundations of their occupational success, and all were deeply rooted in their native Taiwan.

Prosperity Settlement people were for the most part not impoverished, but most were not rich either, and their occupations were not prestigious. To put it bluntly, as a friend from the neighborhood did years later, "it was a very below-average place to live." They knew this. In consequence, my appearance among them made no sense, for they could see nothing about themselves or their community that merited research by a foreign graduate student. As I persisted in trying to learn about their lives, some lost their suspicions (that I was a Christian missionary or was trying to find out the community's secrets for the government), but most politely ignored my presence. In a community where lifelong ties of reciprocity are everything, I did not appear to have much to offer them in return for whatever it was that I wanted. I was young, I was a woman; perhaps, in their opinions, I too must have been "below average" to be doing my research there instead of in Taiwan's important universities and museums.

I had not expected to be so unimportant and uninteresting to my field informants; I was dismayed. After several nearly fruitless months of fulltime attempts to gain rapport, I had a stroke of luck that brought me the help of Chen Fumei, a college graduate from the neighborhood. She was planning to go to the United States at about the time I was scheduled to leave Taiwan. She became my field assistant for the last six months of my stay, introduced me to people, and informally stood guarantor to her neighbors for my good faith. I gave her a salary, helped her prepare for an English-speaking future, and escorted her, when my work was completed, 
to her new married life in Madison, Wisconsin. It was a very happy arrangement and, I am sure, saved my fieldwork.

Through Chen Fumei, I was able to learn some of the things I needed to know to write about Prosperity Settlement as an organized community. But the frustrating effort of studying the neighborhood alone made me aware of other, and interesting, things about Chinese culture and my insertion into it. I experienced the relentless impersonality with which Chinese treat strangers and outsiders, the hermetically closed nature of Chinese primary groups, the practicality on which social relationships are founded, the constant fear of political action or discussion, and the lack of curiosity-and even condescension-expressed toward non-Chinese, whose ways, by definition, are inferior. For a mobile, rapidly urbanizing society heavily dependent on foreign trade and tourism, these were problematical attitudes, worth trying to understand.

I also learned from the contrasts between the behavior of my language teachers and that of Prosperity Settlement people. While my graduate training in anthropology had prepared me for variations within a culture as old, as large, and as internally complex as China's, the difference between Beijing teachers and Taiwanese construction workers seemed great enough to put the whole notion of one Chinese culture into question. Obviously some of that difference stemmed from the fact that with the first group I was known and respected, while with the second I was merely a nuisance. But there was more: subcultural differences great enough to be called "ethnic," differences of occupation, social class, and education, and differences in the fundamental attitude toward Americans as a group, separated them. None of this was clear enough, when I left Taiwan, to be, very satisfactory. I would have to return to unravel the complexities.

In the summer of $1974 \mathrm{I}$ returned to study the connections between Taiwanese-Mainlander ethnicity and social class. Living in a tiny apartment in Prosperity Settlement, I caught up with my friends among the neighborhood people but spent most of my time surveying sections of the city for background on studies of Taiwanese-Mainlander intermarriage, funeral practices, and religious activities. Accompanied and assisted by the most adventurous of my Chinese friends, Wang Chunhua, I collected data from government offices, temples, and people in many neighborhoods as we tried to factor out how class and ethnicity interacted in Taiwan's complex social structure.

Though the work was going well, my health was not, in part because of the discomfort of my living conditions. My apartment-two small rooms, and the shared use of a kitchen, bathing room, and toilet-had been 
partitioned off in a building that had once housed one large family but now crammed in six families, or about forty-eight people. The building was alive with vermin-large mice on the rafters, the occasional rat under the bed platforms, and swarms of two-inch cockroaches everywhere. In hot climates, cockroaches not only slither into dark crevices, including one's clothes, dishes, and the toilet bowl, but they also fly. I am not squeamish, but a large cockroach in one's bed at night encourages insomnia. The house, like nearly all houses in Taiwan, was unheated, though the temperature was in the forties, and the days were raw and rainy for weeks in midwinter. Bathing in a kettle of heated water in a drafty concrete bathing room was an ordeal.

My bedroom was enclosed with glass windows that I covered with whitewash so I could sleep and dress without being observed, although children regularly scratched it off to peek in. My living room was also the passageway through which the neighbors reached our common kitchen and bathrooms. Since those neighbors had four small children, it was not possible to leave anything of importance outside the bedroom, as the younger ones could not resist novelty. Nor could they resist watching me at mealtimes, hoping for a treat. My neighbors slept in a single adjoining bedroom on the same raised platform covered with Japanese matting where I spread my quilts each night. When anyone rolled over in bed, the rest of us felt it; when the newborn baby cried, I heard her mother's murmured, affectionate "Eat, little slave" as the infant slurpily took her breast.

Unlike that comfortable little family, however, I had learned to expect a good deal of quiet and darkness for sleeping, as well as privacy and quiet for eating and working. After six months of poor sleep in these extremely crowded living conditions that most Chinese take for granted, I found myself too ill to continue. While Wang Chunhua carried on several of my projects, I retreated to a friendly haven in the south of Taiwan for a few weeks' rest and recovery. Returning to tie up loose ends in early summer, I had gained a new respect for and curiosity about the personal side of life in a society that offers the individual so little physical and psychic space.

\section{Collecting Life Histories}

My decision to plan a brief field trip in 1980 around the gathering of life histories stemmed partly from this curiosity, but also from other sources. By the summer of 1975 I had met many Chinese people in the course of my work, and a few had shown me glimpses of their personal histories. Each 
revelation had been given in a moment of stress, as if she-they were all women-had lost control of a proper reserve, and let something very private spill over. On one occasion, I met my landlady from Prosperity Settlement by chance at the hairdresser's. As we walked home together, protecting our hairdos under the same umbrella, she poured out a torrent of grievances against her ungenerous old mother-in-law, her feeble husband, and the lifelong, unhappy relationship among the three of them. I was astonished at her candor and at how little of this I had seen or suspected, though I had known her for years and had lived in her house for months. Later I realized that there had been hardly a moment in her crowded, busy life when she might have spoken feelingly with another, in private. How much of the reserve I had felt so strongly from my Chinese friends was due simply to lack of opportunity and hence of the habit of expressing personal feelings? Collecting life histories in a comfortable, private setting might prove a valuable format for learning about Chinese life. And, I hoped, telling about long-suppressed feelings and experiences might, in some way, be helpful and positive for the tellers.

Life histories appealed to me as well, because by 1980 history itself was assuming greater importance in anthropology; researchers now took seriously the idea that we can understand social change and social reproduction only through diachronic perspectives. In addition, in analyzing the emergence of social class and ethnic patterns in Taiwan, I had become increasingly conscious of the absence of historical materials about an extremely significant period - the years of World War II, of the Japanese loss and Nationalist seizure of Taiwan, and of the decade or more of Nationalist misgovernment and economic chaos through the 1950s. Most people flatly refused to discuss those times, while those who would spoke of them guardedly, and only in places where they were certain not to be overheard. My researches into Prosperity Settlement's past and into the emergence of class and ethnic relations had repeatedly been frustrated by these responses. More indirect approaches were called for; perhaps the life histories of people who had lived through these events would give me the dayto-day texture of those times without my having to ask people to speak specifically about them. It was, I think, a Chinese solution. It saved my informants from being put on the political spot, and it worked.

Despite the way it is taught in universities, anthropological fieldwork is not an endeavor carried out by the anthropologist with the full cooperation of members of the society under study. It is often, quite simply, what our field informants allow it to be. I did not unilaterally choose the women and men who told me about their lives, though some of them chose me. I did, 
however, have goals for the 1980 research which guided me in my final decisions about whom to search out and interview and about which interviews I would include in this study.

I wanted to talk with older people-in their sixties, at least-who had lived through the important events of Taiwan's recent past and who had been ordinary working people most of their lives. I wanted women and men, Taiwanese and Mainlanders, city-bred people, and those who had come as migrants to the city. Finally, of course, I wanted people whose lives have been eventful and who could tell of those events with some verve, some insight. Most of the life histories included here meet those criteria, though the group includes one remarkable younger woman whose life has been shaped more by her struggles with personal tragedy than by the results of social change.

I wanted to include people whose stories fill out the historical picture of the chaotic forties and fifties as well as the boom times of the sixties and seventies, in order to show something of the life of working-class people in a great and complex city, and to illustrate the range of contemporary Taiwan Chinese family types and the change in their kinship values. They were chosen, too, to exemplify some of the many variations on a well-lived life as each of these people struggled to attain the Chinese ideal of zuo ren-of "acting as a real human being"-within the limits that life imposed on them.

When I arrived in Taiwan, I contacted several people who I was sure would agree to tell me their stories. They were Mrs. Lim, a Prosperity Settlement neighbor five years ago; Mrs. Zhang, who had cooked for me on my first field trip and had remained a good friend since then; her husband, a retired air force man; and Miss Ong, an old Prosperity Settlement friend whose courage in adversity had kept mine up during my first fieldwork. I also hoped to get help from some of these people in persuading mutual friends whom I knew less well to talk to me; Mr. Kho's story is one result of these attempts.

A few other attempts failed. When the subject of -an interview was broached, two or three acquaintances indirectly refused, saying that their lives were of no interest, that they were too busy, or simply giving the allpurpose Chinese excuse that such interviews were "not convenient." A few others gave me nothing but the barest chronology of their lives, and I found no questions that prompted them to become more expansive. One younger woman, a taxi driver, told me, "Most of life is very simple. We go through our days, getting by, and that's that. What is there to tell?" Not surprisingly, the shorter our acquaintance, the less likely people were to dig into their memories for my tape recorder. 
Two of the people chronicled here essentially proposed themselves to me: Miss Guo and Mr. Kang both offered to tell me about themselves after watching me going about my work for some weeks, and Miss Guo invited Mrs. Lo to do the same.

Having found a woman willing to talk about her life, I invited her to my comfortable private room in the hostel where I was living. (No more sleepless nights in Prosperity Settlement this time, I vowed.) With men subjects, I made it clear that the interview would take place in the hostel's quiet public lounge, a respectable-enough location in which to meet a foreign woman. All, however, to my great pleasure, insisted that we conduct the interviews at their homes, giving me the opportunity to learn things about their lives that words do not easily convey. Most of them arranged for considerable privacy for our talks.

As we began, I explained my ground rules. I would like to tape our conversations, but in any case would put as much as I could of what they told me in writing. I would publish the material, in English, in the United States, but an English edition might possibly appear in Taiwan as well. I would not let anyone in Taiwan read or hear what they had told me in the original Chinese, except for my two field assistants. I would change family names to protect their privacy.

For some, these guarantees of anonymity seemed to be a relief, but a few were surprised by them. "My name is my name, and my life an honest one. There is no need to hide anything," said Mr. Zhang. To such responses, I replied that the book would contain not only their words but also my ideas and explanations, with which they might not completely agree: after all, they are Chinese and I am American, so our viewpoints might differ on some subjects. When the book was published, it would be best that I completely bear the responsibility for the contents. To this they all agreed.

In conducting the interviews I decided that, wherever possible, I would encourage people to tell their stories with little interruption or direction from me, although I asked them to speak especially about their work lives. At least initially, I wanted their version of their lives rather than a set of answers to questions I had framed. I did not want to press them unduly on matters that might embarrass or discomfit them, and I trusted most of them to speak frankly, if not with complete openness. Naturally, had I been more directive and pressed harder for certain details, I might have learned other interesting things. But at the same time, I might have gone too far, deflecting someone from the line of remembrance she thought most meaningful and rupturing the friendly confidence that made the interview possible. Ultimately, I think, I did not want to hurt or offend people who had generously agreed to share something of their inner lives with me and 
with an unseen reading public, and preferred to respect their choice of expression.

For the people whose stories are published here, this approach worked well. Here and there the reader will notice events, skimmed over vaguely at first mention, which the speaker later clarifies, as when Mr. Kang reveals his dramatic escape from the Communists which prevents his contacting his family. Mostly, however, people structured their descriptions of events around a dogged historical approach-my ancestors, my early childhood, my growing up, my marriage, and so forth-modeled after the many biographies of "virtuous people" to which most people have been exposed in school.

It is difficult to tell the story of one's life convincingly while leaving out significant events. The very telling calls up memories and feelings that carry the speaker along unself-consciously to reveal much, if not all, of what she has experienced. Not having worked much with a tape recorder before, I was surprised at how little attention informants paid to it, or to me, when they were deep into reviewing the memories that constituted their selves.

Occasionally, when I understood poorly the meaning of what was said or needed to ask a question, I stopped the flow of reminiscence for clarification. Sometimes the field assistant added a question or comment. Often we slacked off to eat, drink, or chat about peripheral matters, when the informant seemed to need a break. These were pleasant hours, though the memories I was hearing were often sorrowful ones. We usually worked about two hours at a time, and we returned four or five times to most of the informants.

How to make an appropriate return for an informant's time and trouble is a matter that often bedevils anthropologists. In Taiwan this matter was simplified by the fact that the Chinese follow an elaborate code that specifies what gifts to give and when to give them. To people I did not know well, I brought the kinds of presents given when one visits for the first time or asks a small favor-baskets of choice fruit and tins of cookies. For old friends with whom I was already linked by the gifts we exchanged on special occasions, the treats could be more closely matched to their tastes: the Zhangs like pig-ear shreds and sesame buns from a special shop; Miss Ong enjoys Tainan-style candied fruit. When I finished each interview, I brought a more substantial present: a dress length of fine mainland silk, well-made woolen sweaters, a small tape recorder, a bottle of unusual liquor. In a couple of cases I added gifts of money, properly concealed in the traditional red envelope, for a child or grandchild. I knew also that all these people would now feel free to ask favors of me: helping with a child's 
English studies, or sending or receiving foreign currency, for exampleknowing I would do my best to comply.

As is customary among Chinese people, I always gave copies of snapshots to people I had photographed. Such exchanges are important in Chinese society, where friendship is expected to express itself tangibly as well as symbolically. Many Chinese people are, by Western standards, quite sentimental about friendships, and love to have photos, souvenirs, and objects around them that remind them of happy occasions. I was glad I knew how to give appropriate gifts, and glad to give them. They helped knit me, a foreigner, into the fabric of a Chinese relationship by showing informants that I understood important Chinese cultural rules and standards, thus making me familiar and trustworthy despite my alien appearance and origin. Mutual usefulness framed by etiquette that demonstrates respect for each other's dignity comes close to being a definition of Chinese friendship. By 1980 I was comfortable with relationships that were so defined.

Two graduates of the anthropology department of National Taiwan University, Miss Zhang Xun and Miss Zhang Huiduan, contributed significantly to this project as field assistants, accompanying me on interviews, transcribing and translating, and carrying out a number of additional investigations. For some informants, the assistants' ties with the university gave my undertaking an additional air of dignity, for though two or three of the subjects had heard of such famous American universities as Hafo (Harvard) and Yelu (Yale), none of them was sophisticated enough to be familiar with Central Michigan University, my home base. It was reassuring for those who did not know me well that I had scholarly connections in Taiwan through the Miss Zhangs.

Both of these women possess unusual intelligence, charm, and tact. As Chinese people who have agreed to help one in a long-term way will nearly invariably do, they put their talents at my disposal, working enthusiastically and resourcefully at the tasks I set before them. Good interviewers themselves, they often found ways to pose clarifying questions to our subjects or to spot and resolve ambiguities that I might have overlooked. As they were reared in cultivated families, their polished etiquette and verbal mannerisms helped make up for the lapses of language and courtesy that I no doubt continued to make.

At the same time, they remained unobtrusive in interviews. There was little difference in the confidence shown me when I interviewed alone (as I did most times with Mandarin-speaking subjects) and when one of the Miss Zhangs accompanied me. The interview subjects treated them as my 


\section{Chinese Working-Class Lives}

lieutenants, apparently assuming that if I trusted their discretion, so could they.

When a life history was completed, I turned the tapes over to one of the field assistants for transcription into Chinese characters. This was not an entirely simple matter, for many informants spoke in the Taiwanese language commonly used by the native Chinese population of the island, rather than the "national language" (Mandarin) in which educated younger people are accustomed to write. While in theory any Chinese language can be written in the same ideographic characters used for Mandarin, in practice there are differences of grammar and of word usage in nonMandarin languages such as Taiwanese which require special characters and conventions that have not been taught in Taiwan's schools for many decades. Taiwanese, which used to have a flourishing literature, has thus been reduced to a nonwritten language. The assistants' character transcriptions for Taiwanese-language tapes, therefore, contain some oddities. Tapes from one of the post-1949 Chinese immigrants to Taiwan, Mr. Zhang, presented similar problems, as he speaks in a Mandarin that is heavily influenced by the accent and speech forms of his native regional dialect. Just such variability in spoken Chinese in Taiwan-two major languages and many strong regional dialects-made the assistance of my field helpers a necessity and, through the companionship we shared, a pleasure as well.

From the Chinese-character transcription, the Miss Zhangs made rough English translations, which I later recast and edited. The final versions are considerably compressed from the elimination of repetition and extraneous conversation.

The major difficulty in final preparation was the problem of preserving, through translating and editing, a sense of the spoken style and personality of the informants, who range from well educated to illiterate, from earthy and direct to floridly euphemistic in their diction. Each also spoke in turns of phrase appropriate to her or his age and sex, using expressions drawn from many Chinese regional rhetorics. Though the English versions lose nearly all this verbal variety, I have attempted to retain some distinctions among the voices, sometimes by the substitution of English idioms for what was actually said in Chinese. Though these life histories are, I think, true to the spirit of the originals, they are not simply transcriptions from the tapes. If they could read them as they stand, however, I believe their subjects would readily recognize themselves.

The Chinese women and men whose life histories I collected lived through the dramatic changes of the last sixty years and also learned from others' memories about conditions of earlier times. Their experiences represent a side of Taiwan's history that is rarely written down and hence 
easily ignored: that of the working class. They saw economic, political, and social change from the point of view of people with limited power and resources and a very incomplete knowledge of the national and international events occurring around them. Like most people, they evaluated these by how they themselves were affected.

They sometimes misunderstood events beyond their immediate experience and usually emphasized those events in which they had special interest while ignoring others, or they simply omitted reference to painful or troublesome times. Sometimes, too, they may have misrepresented events deliberately. But all these things are done by anyone, even a historian: no one knows everything about the past or sees it from some abstract, inhumanly objective point of view. Indeed, it can be argued that an ordinary person's view of recent history is more balanced than that of a professional historian. For while society's elite (to whom most historians belong) may know next to nothing about the day-to-day realities of workingclass life, working-class people like my informants not only know their own circumstances, but are also often well instructed, through schooling and the public media, in the "official" view of history and current events that their leaders put forward and which form much of the material for later historical studies. The views of ordinary people can therefore be quite complex, and sometimes contradictory. As a result, a life history is not a simple, factual description of the past that everyone would recognize as accurate, though it may superficially appear to be. Rather, it shows us both the impact of external events on a particular person, and an attempt by that person to construct a meaningful pattern out of those events. A single life history, taken alone, gives only a limited picture of anything beyond the individual who creates it; several overlapping lives show us something both of the individuals represented and of the shared experiences that make up a people's history and culture.

\section{"What Is an Anthropologist, Anyway?"}

Anthropology fieldwork, whether interviewing for life histories or collecting impersonal information about customs, kinship, economic activities, and the like, always begins with the anthropologist as a single human inquirer. She has a theory to test, or at least a plan of approach, and has acquired some prior knowledge about the people from whom she expects to obtain information. One of the biggest imponderables in the field situation is the response she will receive based on the kind and degree of knowledge her subjects have about "outsiders." With no training for cross-cultural 


\section{Chinese Working-Class Lives}

encounters, little information about foreigners, not much sense of cultural relativity, and often not even much curiosity about "their" anthropologist, the people about whom anthropological studies are written confront researchers as unprepared, and often unwilling, informants.

"What does she want?" "What will I gain if I give it to her?" "What can she do to me if I refuse?" are natural questions, as a strange-looking foreigner who speaks awkwardly and is generally deficient in politesse attempts to strike up a conversation, loiters to observe one's family funeral, or simply watches, scribbling foreign writing in her ever-present notebook.

Such a stranger is classified in the broadest possible terms at first. In some small-scale societies, it is even doubtful at first whether the anthropologist is even a human being, though this was not true in Taiwan. People unused to different styles of grooming and dress may find difficulty in determining something as basic as the visitor's sex. An American friend used to tell with amusement of how his elderly Taiwanese landlady had had to ask whether, despite his full beard, he was male or female, "because your hair is long, like a woman's." On being told that the beard should have been indicative, she shrugged, "American customs may be different, for all I know." In my case, my gender confused no one; I was clearly and disadvantageously a woman in a very sexist society.

My age, however, was a source of confusion to Chinese people unaccustomed to Caucasian faces. As a student and a married woman without children, I must be young, they thought, but I did not look it. Just as Americans often guess Chinese to be younger than they are, we look older than our age to them-a result of our "craggier" faces, deep-set eyes, and tendency (at least among graduate students) to premature wrinkles and gray hair. As age is an important status consideration for Chinese, this is a small advantage in gaining the respect due an adult. Its impact was lessened, however, by the apparent inconsistency between the "young" student and the "older" appearance, which gave people mixed signals about how to treat me.

My educational status, by contrast, placed me in a clearly positive light, for it suggested that I must be a person of elite status. The Chinese admiration for education exceeds that of most Americans; saying I was a student of their language and culture brought warmth and respect from nearly everyone. This familiarity with educational attainment did not, in general, include an acceptance of the anthropological position that the lives of ordinary people were worth studying, however. Even my educated Mandarin teachers disapproved of my taking time to study the Taiwanese language, which they saw as the coarse dialect of lower-class people. But, as I traveled around the city meeting people, I was always treated more 
helpfully when I revealed that I was pursuing, or, later, had attained, the lofty-sounding bo shi-Ph.D.-degree.

Furthermore, being identified as an educated person, I would, it was assumed, know some especially effective way to teach English. I was constantly besieged with requests to teach, formally and informally, and in fact did teach English in colleges, cram schools, government bureaus, and in my own living room. At first, I did so to finance my language studies, and later, as a service to friends. People approached me on buses and on the street with the frank suggestion: "Let's be friends, so you can teach me English." When for lack of time I turned down such requests, I knew I was perceived to be refusing to enter into a relationship. Only after some experience did I learn to respond as a Chinese would be likely to do, by agreeing to teach someone, so as to convey my openness to forming a friendship, but then to let the lessons trail off after only one or two meetings.

Though such matters are difficult to pin down, I believe that perceived relative social class status also affected my relationships with many Chinese (as it does in American society). Working-class people were typically less willing than "middle-class" ones to deny requests when I pressed hard, and may have hoped that my "higher" status might make me a useful contact for them. By contrast, Chinese whose education and class status was equivalent to or higher than mine were much harder for me to form relationships with. Perhaps this was because I had nothing much to offer in return for what I hoped for in the way of information and contacts from them. While it was unpleasant to recognize this, I came to conclude that I learned more about Taiwan's working class than about its elites largely because our relative prestige permitted me, at times, to inflict myself on some people but not on others. Many anthropologists must experience this biasing "advantage" in their work.

For the Chinese, whether new acquaintances or old friends, my most dominant characteristic, however, was my identity as an American. It was Meiguo ren (in Mandarin) or Bikok lang (in Taiwanese)_- American person"- -that was shrieked at me by children in the streets, and only rarely the generic da bizi (big nose) or yang guizi (foreign devil), which distinguish race rather than nationality. It was as an American that I was introduced, discussed, described; the word for "friend" in Mandarin, pengyou, usually refers to non-Chinese only with a qualifier: a Meiguo pengyou (American friend) or a waiguo pengyou (foreign friend). American nationality was clearly my most salient and, for most people, my only significant identity.

A strong sense that the Chinese I was meeting responded more to their own stereotypes of Americans than to me pervaded my first field trip, 


\section{Chinese Working-Class Lives}

partly for the purely personal reason that in those years I acted more like an American. There was another important reason behind this stereotyping, however. Although it was not my intention, or my desire, to appear in this light, many Chinese saw me first and foremost as a representative of a country that has profoundly influenced Taiwan's society, often in ways of which they disapprove.

One powerful shaper of the perceived identity of any American in Taiwan at that time was the Vietnam war. The United States considered the Nationalist government an ally in that war, with the aims of which, as ardent anti-Communists, the Nationalists were in full sympathy. Under that alliance, the United States made massive purchases of building materials-mostly cement-from Taiwan's state-controlled cement company for the construction of bases and fortifications in South Vietnam. This gave a welcome boost to the island's export economy and made a small number of people extremely rich. The Nationalist government in return permitted the United States Army to use Taiwan as an official "R and R" (rest and recreation) post for its soldiers.

During the war years, Taibei swarmed with American soldiers looking for women, liquor, and souvenirs. Tourism and prostitution boomed, as did procuring of prostitutes by both officials and underworld gangs to meet the apparently endless demand. Pimps scoured poor hinterland villages for parents desperate or callous enough to sell daughters, many as young teenagers, into this ugly life. The sale of cement and women earned dollars but not admiration from thoughtful Chinese who saw the cost: the expansion of a corrupting underworld in which their government colluded. Military tourists were the Americans whom most Chinese encountered.

The Vietnam war, however, was only one facet of the decades-old relationship the United States has maintained with Nationalist China. I will explore this relationship further in the next chapter, where I examine the island's history and its resulting social organization. The long-term American-Chinese connection has left deep impressions on many Chinese minds, and many of these impressions are unfavorable.

The Chinese are a cautious as well as a courteous people, and do not commonly court confrontation by stating their resentments of Americans openly. Just once, in all my meetings with Chinese people in Taiwan, did I hear flatly and directly the hostile words that, because of the history of our national relationships, many Chinese people keep to themselves. These words were from a five-year-old girl.

Six months into my first stay in Taiwan, in early 1969, I was standing with my former husband, a tall, bearded, and, to Chinese children, somewhat intimidating "foreigner," waiting for a Taibei city bus. Riding back and forth 
on a smooth stretch of red-tiled sidewalk was a very small and very energetic little girl, intent on steering her tricycle.

Greedy for opportunities to practice my Mandarin with someone who could not immediately out-talk me, I opened conversation with a conventional, "Little sister, have you eaten yet?"

Her only response was a sidelong and distinctly unfriendly look. I tried again: "Little sister, come on over! I want to be your friend."

This provoked a response, and a remarkable one, as little Chinese girls are usually very timid, especially before big, bearded foreigners.

Suddenly, but emphatically, she said, "I don't want to be your friend."

"Why not? We can be friends. I like you."

"Well, I don't like you. You're American, aren't you?"

"Yes, American."

"I hate Americans. Americans sold out my country to the Communist bandits, so I hate all of you. My daddy says so."

Astonished as much by her vehemence as at hearing this level of political discourse from a preschooler, I tried to persuade her that Americans and Chinese were often friends. She was not to be persuaded; she was so angry as to be quite unafraid; she hated me, she hated Americans, and she rode away.

For once, I had heard an unmistakably honest voice on the subject of United States-China relations. The opinions, of course, came from her father, but she had heard them often enough, it appeared, to have them firmly fixed in her mind. Her family had obviously immigrated from the mainland, an assumption confirmed by her standard-accented Mandarin, which a Taiwanese child of her age would not have mastered in those times. How many Mainlander children have grown up in Taiwan hearing the same sentiments-that the United States failed to back the Nationalist government strongly enough to assure victory over the Communists in the late 1940s, thereby condemning them to exile in alien Taiwan?

I have never heard such harsh criticisms from native Taiwanese, but they too have their reasons to resent Americans. During World War II, when Taiwan was under Japanese rule, American forces heavily bombed Taiwan's cities. In addition, many educated Taiwanese blame the persistence of unpopular Nationalist power under the leadership of Jiang Jieshi (Chiang Kai-shek) on American support he received after fleeing to the island in 1949. "At the end of the war," goes a Taiwanese saying, "the Americans dropped the atomic bomb on the Japanese, and dropped the Jiang family on us. If they had only atomic-bombed us, and dropped the Jiangs on Japan!"

The dislike, and even hatred, that some Chinese feel for Americans is not simply a direct response that grew out of experiences since World War II. 


\section{Chinese Working-Class Lives}

Before that time, the mainland of China had suffered very extensive economic and political colonization by foreign nations, including the United States. These had enforced humiliating unequal treaties that prevented the normal exercise of sovereignty by Chinese over their land, people, and revenues for decades. Generations of Chinese leaders grew up in a complex intellectual atmosphere of admiration for Western achievements, mixed with bitter resentment of the power that Westerners were able to exercise. On the mainland and later in Taiwan, the Nationalists actively taught a nationalistic doctrine glorifying the Chinese as a separate and superior racial group with undying hatred for the foreigners' unequal treaties. Such ideas, by the time I came to Taiwan, were a part of the education of every schoolchild and were widely propagated by the government.

Some of these attitudes are understandable reactions to the aggressive imperialism of the Americans, British, Russians, Japanese, and other peoples who colonized China. Because these are official party positions, they carry weight even with young people who have no personal experience with the war or the chaotic century that preceded it. As an American, I too was tainted with this heritage.

In spite of all this, many Chinese were willing to distinguish between abstract "Americans" and real-life examples, and to treat me as a person. Indeed, many Chinese have a good deal of admiration for some aspects of American culture-its technology, its lively popular entertainments, its generosity - which they had encountered as military men back on the mainland or as recipients of the post-1949 flow to Taiwan of United States economic aid and emergency relief. This admiration, although pleasant to experience, is, I believe, both narrow and shallow.

Whole areas of American life are as unknown and alien to Chinese people as their lives are to us, and their judgments about us are often based on "facts" that seem oddly distorted. Though the actual knowledge most ordinary people have about our society is, in fact, quite slight, Chinese people are not, in general, very curious about American life. In return for my questions about their lives, people asked what I paid for rent, clothing, and the like back home (all perfectly proper questions in Chinese society), and what I thought about popular figures such as presidents and movie stars, but they never displayed much interest in other subjects.

In addition, they wanted very much for me to affirm to them certain beliefs about American families which have gained currency in Taiwan. These ideas about our family life show us as a people who, by Chinese standards, lack the most basic morality. One belief that was constantly repeated to me was that when an American parent visits a married child, she or he is charged room and board, even if for only a single meal. Com- 
monly, unsophisticated Chinese also believe that when our senior relatives die, we promptly forget them "as you would a dog," "because that is the Christian custom." At first I used to deny that this level of disregard was common, but I always found my hearers unconvinced. These beliefs about us contrasted so vividly with their own beliefs about themselves-that parents are always treated generously by married children and their spirits are remembered in family rituals long after death-that they had become incontestable evidence for a deeply felt sense of moral superiority of Chinese over Americans. Americans may have money and gadgets and Disneyland, but Chinese have the cultural formula for correct and enduring human relations, which are, ultimately, what really matters.

The people whose life histories I include here shared some of these mixed attitudes toward Americans, of course, for they permeate Taiwan's culture. If there is one serious drawback to my method of learning about Taiwan's working class through life histories, it is that because I am an American whose nationality has negative associations, the impact of the extremely important American influence in Taiwan was not easy for informants to speak about. People who knew me only slightly would think it an act of rudeness toward me as a person, and possibly slightly dangerous, to mention the military bombings, corporate exploitation, and interference in foreign relations my country has perpetrated on Taiwan.

As I pondered this problem in the field, I realized that nearly every American anthropologist is caught in the same paradox. When we study a society that has been strongly affected by American political, economic, and cultural influences, those who will speak to us are, by and large, those who do not see, or out of courtesy do not discuss with us, their negative consequences. Those who see them most clearly may avoid us, or be silent. What would an Indian anthropologist have heard from my Chinese subjects? How much of what I have learned stems from my Americanness, and how much from their Chineseness? I shall never know.

\section{Fieldwork and Politics}

For me, the most difficult part of becoming more like a Chinese was setting aside my interest in politics. Americans, I realized for the first time in Taiwan, discuss politics a great deal, treating an election, a government scandal, or the latest war as a subject for small talk, like the weather or the fortunes of a favorite ball team. Most Americans speak as though they believe their government is their personal business, about which they have every right to have opinions. Such outspokenness on matters of state shocks 


\section{Chinese Working-Class Lives}

Chinese people in Taiwan, where it is not only in bad taste but downright risky to criticize the government. An educated person is expected to know the government's position on important matters and to repeat it when necessary. Uneducated persons (and women) are expected to refrain from commenting on "national affairs" altogether.

Taiwanese men especially do discuss politics, of course, but much more cautiously than Americans, reserving their opinions for trusted intimates. A very large and efficient network of party activists, secret police, and paid informers is quite likely to pick up and report criticism of the authorities to those same authorities. Serious criticism is seen as evidence of Communism, and hence of treason. Investigation, blacklisting from government employment, prison, or death have been the well-known consequences of such treason, so people watch their tongues.

Taiwan's politics continued to fascinate me, however, and at first I probably contributed to the "pushy" image of Americans by excessive probing for people's "real" political opinions. I soon learned that most people were simply not going to trust me that far. The very fact that I had asked openly about such matters showed I had no political sense and might get my respondent into trouble. As I modeled my behavior to resemble that of a Chinese, I too learned to hold my tongue, waiting for the occasional quiet political confidence.

\section{Becoming a Little Chinese}

Despite an understandable strain of Chinese antipathy toward Americans, despite the cultural reticence of Chinese toward strangers, and despite my limitations as a fieldworker, time and my efforts to learn other ways of behaving have made me some good friends in Taiwan. At times, Chinese friends remark that I have treated them as a Chinese would; on a few occasions, in a dark taxi or on the telephone, I have been mistaken for a Chinese. From people who esteem their own ways so highly, this is praise.

But becoming a little like a Chinese has made me uncomfortably conscious of a contradiction between an acceptance of that intimacy and the anthropological goal of revealing a whole culture, not merely the smooth formal face it presents to strangers. Does one not betray trust by publishing friendly confidences? Friendship with such an end in view seems insincere: friends keep one's secrets, especially in China. Educated Chinese, knowing their society has held an internationally weak and culturally devalued position for over a century, sometimes resent the apparent "objectivity" that shows Chinese culture "warts and all" to the outside world. 
I think the working-class people who have told me their life stories will be tolerant of what I have learned from our friendships, even if they were to disagree with my conclusions or object to my airing of some of their national dirty linen. Their tolerance comes from self-confidence, a class culture little affected by alien values, and from their clear-eyed attitude that Taiwan's current society has both its strengths and weaknesses, its points of pride and occasions of embarrassment. When I told them I wanted to write as honestly as possible, even about bad things, they agreed that only in that way can future generations learn from them. 